\title{
Stent Implantation and Subsequent Dilatation for Pulmonary Vein Stenosis in Pediatric Patients Maximizing Effectiveness
}

\author{
Hideshi Tomita, MD; Ken Watanabe, MD; Satoshi Yazaki, MD; \\ Kohji Kimura, MD*; Yasuo Ono, MD; \\ Toshikatsu Yagihara, MD**; Shigeyuki Echigo, MD
}

\begin{abstract}
The outcome of stent implantation and redilatation was investigated in 4 pediatric patients with 7 stenotic lesions of the pulmonary vein (PV), paying particular attention to late neointimal proliferation. The minimal diameter of the lesions increased from $0.8-3.6(2.3 \pm 1.1) \mathrm{mm}$ to $3.6-8.4(5.1 \pm 1.6) \mathrm{mm}$ immediately after stent implantation. Although the pressure gradient across the lesion was not measured in patient 4 , in patients $1-3$, it decreased from

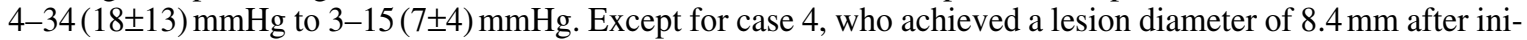
tial stent dilatation, the other 6 lesions all restenosed within a few months, with an increasing pressure gradient. One patient with multiple PV stenoses associated with persistent severe pulmonary hypertension died suddenly. However, repeat dilatations were effective in all other lesions. Furthermore, in one lesion in patient 1, no serious restenosis developed for 20 months after the lesion was dilated up to $5.6 \mathrm{~mm}$. Although further follow-up is mandatory, the final stent diameter within a vessel may determine long-term patency, and aggressive redilatation may be crucial for successful therapy of such a difficult disease. (Circ J 2003; 67: 187-190)
\end{abstract}

Key Words: Dilatation; Patency; Pulmonary vein; Stenosis; Stents

$\mathbf{T}$ he prognosis for patients with congenital or acquired pulmonary vein $(\mathrm{PV})$ stenosis is usually poor; to date neither surgery nor balloon dilatation has achieved a satisfactory outcome! ${ }^{-7}$ Although implantation of stents is now widely used for various stenotic lesions in the great vessels, ${ }^{8-15}$ stent procedures for PV stenosis in children have been complicated by late restenosis associated with marked neointimal proliferation! ${ }^{10,16,17}$ We investigated the outcome of stent implantation and redilatation for pediatric PV stenosis, with particular attention to late neointimal proliferation.

\section{Methods}

We attempted stenting in 4 patients with 7 stenotic lesions of the PV. Cases 1 and 3, with total anomalous pulmonary venous connection (TAPVC), developed bilateral pulmonary vein occlusion and stenosis at 3 months and 1 month, respectively, after repair of TAPVC. In case 3, an atrial septal defect was created during surgical relief of stenosis to facilitate a transcather approach to the lesion. Despite surgical revision and several balloon dilatations, restenosis occurred each time and was complicated by severe lung edema. Consequently we decided to implant stents to improve the hypoxia associated with pulmonary edema.

(Received August 29, 2002; revised manuscript received November 14, 2002; accepted November 25, 2002)

Departments of Pediatrics, *Radiology, and $* *$ Cardiovascular Surgery, National Cardiovascular Center, Suita, Japan

Mailing address: Hideshi Tomita, MD, Department of Pediatrics, Sapporo Medical University School of Medicine, South-1, West-16, Chuo-ku, Sapporo, Hokkaido 060-8543, Japan. E-mail: tomitah@ sapmed.ac.jp
In cases 2 and 4 , unilateral PV occlusion and stenosis were detected at 13 and 12 months, respectively, after surgery. Cardiac catheterization prior to surgery had not suggested any obstruction and we did not manipulate any of the PVs during surgery. Consequently we could not determine the cause of the obstruction. Although the definitive surgery for the cardiac defects of these patients would have been a Fontan type operation, we did not recommend this for these patients because of poor ventricular function, pulmonary venous obstruction, and pulmonary arteriovenous fistula. Instead we decided to implant stents as a palliative procedure to improve hypoxia (Table 1).

\section{Stent Implantation}

We implanted Palmaz stents (Johnson \& Johnson Cordis, Miami, FL, USA) in cases 1 and 2, and in the left upper PV in case 3, from the groin through a 7 or 9Fr long sheath? ${ }^{8-10}$ Because an acute and tortuous route made it difficult to implant the original Palmaz stent, we implanted Palmaz Corinthian stents (Johnson \& Johnson Cordis) in the 2 lesions of case 3 , and in case 4 . The original Palmaz stents were manually crimped onto high pressure Cordis Power Flex or Opta balloons. The diameter of the balloon was equal to or $1 \mathrm{~mm}$ greater than the diameter of the reference vessel. Palmaz Corinthian stents, which were premounted on high-pressure Cordis Opta LP or Jupiter balloons, were implanted through 6Fr long sheath from the groin, except in the case of the right lower PV of patient 3 where we did not use a long sheath. After initial deployment, stents were further expanded as necessary with larger diameter or higher pressure balloons to leave minimal residual stenosis. We used several types of high-pressure balloons in the redilatation procedures (Table 2 ). Intensive anticoagulation therapy with dipyridamole and coumadin, and tranilast was 
Table 1 Characteristics of the Subjects

\begin{tabular}{|c|c|c|c|c|c|}
\hline $\begin{array}{l}\text { Case } \\
\text { no. }\end{array}$ & $\begin{array}{c}\text { Age } \\
\text { (months) }\end{array}$ & $\begin{array}{l}\text { Weight } \\
(\mathrm{kg})\end{array}$ & Gender & Diagnosis & Previous surgery \\
\hline 1 & 14 & 4.6 & $F$ & $\begin{array}{l}\text { RISO, CAVC, DORV, TAPVC (mixed type), } \\
\text { mild PS, bil SVC }\end{array}$ & $C P V$-LA anastomosis, rt $P V O$ repair and $C A V V$ plasty \\
\hline 2 & 29 & 9.2 & $F$ & $T A, V S D, A S D, P S$ & $\begin{array}{l}\text { BDG and VSD closure with fenestrated patch, ASD } \\
\text { enlargement }\end{array}$ \\
\hline 3 & 20 & 5.2 & $M$ & TAPVC $(I a)$ & TAPVC repair, $P V O$ repair \\
\hline 4 & 41 & 9.6 & $M$ & $P A$, unguarded tricuspid orifice, $P D A$ & rt $m B T$, lt $m B T$, rt $m B$ T ligation, and lt $P V O$ repair \\
\hline
\end{tabular}

RISO, right isomerism; CAVC, common atrioventricular canal; DORV, double outlet right ventricle; TAPVC, total anomalous pulmonary venous connection; PS, pulmonary stenosis; bil SVC, bilateral superior vena cava; TA, tricuspid atresia; VSD, ventricular septal defect; ASD, atrial septal defect; PA, pulmonary atresia; PDA, persistent ductus arteriosus; CPV, common pulmonary vein; LA, left atrium; rt, right; PVO, pulmonary vein obstruction; CAVV, common atrioventricular valve; BDG, bidirectional Glenn; $m B T$, modified Blalock-Taussig shunt; lt, left; up, upper; low, lower.

Table 2 Stent Implantation and Redilatation

\begin{tabular}{|c|c|c|c|}
\hline Case no. & Lesion & Implanted stents & Redilatation \\
\hline \multirow[t]{2}{*}{1} & Left upper & $\begin{array}{l}\text { P154 on Opta } 4 \mathrm{~mm} \text {, post dilatation with Power Flex } 5 \mathrm{~mm} \\
+ \text { P154 on Power Flex } 6 \mathrm{~mm}\end{array}$ & Savvy $6 \mathrm{~mm}$, Opta 6mm, Blue Max $206 \mathrm{~mm}$ \\
\hline & Right lower & P104 on Opta $4 \mathrm{~mm}$ & $\begin{array}{l}\text { Savvy } 5 \mathrm{~mm} \text {, Opta } 6 \mathrm{~mm} \text {, Blue Max } 206 \mathrm{~mm} \\
\text { Power Flex } 7 \mathrm{~mm}\end{array}$ \\
\hline 2 & Left lower & P188 on Power Flex $9 \mathrm{~mm}$ & None \\
\hline \multirow[t]{3}{*}{3} & Left upper & P206 on Opta $6 \mathrm{~mm}$, post dilatation with Power Flex $7 \mathrm{~mm}$ & Power Flex $7 \mathrm{~mm}$ \\
\hline & Right middle & $P Q 154 B L S+P Q 156 B L S$ & Power Flex $6 \mathrm{~mm}$ \\
\hline & Right lower & $P Q 155 B L S$ & Power Flex $6 \mathrm{~mm}$ \\
\hline 4 & Left lower & $P Q 185 B J S$ & Power Flex $6 \mathrm{~mm}$ \\
\hline
\end{tabular}
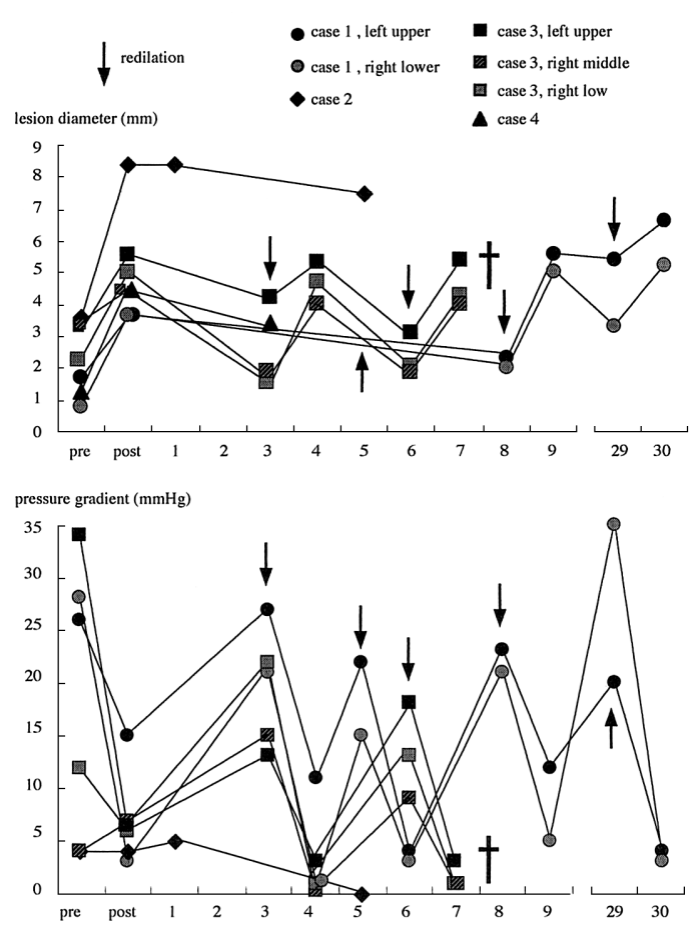

Fig 1. Changes in lesion diameter and pressure gradient.

given after the stenting.

Written informed consent for stent implantation and cardiac catheterization was obtained from the patient's

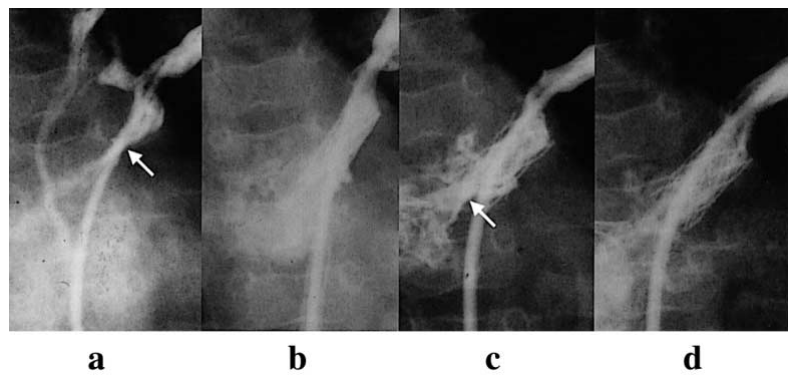

Fig 2. Selective angiograms of a left upper pulmonary vein in case 1 . (a) Prior to implantation of a stent (arrow indicates stenosis). (b) After stent implantation. (c) $\mathrm{F} / \mathrm{U}$ angiogram at 8 months (arrow indicates restenosis). (d) F/U angiogram at 29 months. Restenosis was trivial.

parents.

Data are expressed as mean \pm SD. Statistical comparisons were done by paired t test using StatView 5.0 software (SAS Institute, Cary, NC, USA). A $p<0.05$ was considered statistically significant.

\section{Results}

The minimal diameter of the lesions increased from $0.8-3.6(2.3 \pm 1.1) \mathrm{mm}$ to $3.6-8.4(5.1 \pm 1.6) \mathrm{mm}$ immediately after stent implantation $(\mathrm{p}<0.01$, Fig 1$)$. We could not measure a pressure gradient across the lesion in case 4, but in cases 1-3, it decreased from 4-34 (18 \pm 13$) \mathrm{mmHg}$ to $3-15(7 \pm 4) \mathrm{mmHg}(\mathrm{p}<0.05$, Fig 2). Although severe pulmonary hypertension persisted in cases 1 and 3, in whom bilateral pulmonary venous obstruction had existed more 
Pulmonary vein stenosis

rt up and lt low occlusion, rt low and lt up stenosis

lt up occlusion, lt low stenosis

rt up and lt low occlusion, rt middle, low, and lt low stenosis

lt up occlusion, lt low stenosis

than 1 year prior to stent implantation, lung congestion was ameliorated in all other patients.

Except for case 4, whose lesion diameter increased to $8.4 \mathrm{~mm}$ (Fig 3), restenosis with an increasing pressure gradient occurred in the other 6 lesions, developing within a few months. Case 3 had persistent pulmonary hypertension 6 months after the last redilatation of the stent and died suddenly. However, repetitive redilatations were effective in all other lesions. Stent diameter increased in every redilation from 4.2-6.8 (5.2 \pm 0.9$) \mathrm{mm}$ to $4.4-6.9(5.7 \pm 1.0) \mathrm{mm}$, though the increase was not statistically significant. The intimal thickness significantly decreased from $0.1-3.7(2.3 \pm 1.1) \mathrm{mm}$ to $0-1.5(0.8 \pm 0.6) \mathrm{mm}(\mathrm{p}<0.01)$. In the left upper PV of case 1 , there was no evidence of serious restenosis for 20 months after redilatation of the stent to $5.6 \mathrm{~mm}$ using an extra high pressure balloon at 8 months after the initial stent implantation (Figs 1,2).

\section{Discussion}

Pulmonary vein stenosis may occur as an isolated lesion in patients with an otherwise normal heart, but more frequently coexists with such congenital heart anomalies as TAPVC, transposition, and other anomalies.2,18-20 Although affecting a small number of patients, recurrent post repair PV stenosis may be lethal if it develops bilaterally, 1,3,6,7,20 In patients with right isomerism, the presence of an obstructed PV is an independent risk factor for a poor prognosis ${ }^{21}$

A previous study suggested that the presence of echocardiographically defined turbulence within the PVs after repair is associated with restenosis,2 and another study reported that the size of the individual PVs was an important determinant of outcome in patients with TAPVC? Although pediatric data on the outcome of intravascular stent implantation for pulmonary artery and systemic vein stenosis suggests an exceptionally high patency rate, stent procedures in children with congenital or post repair PV stenosis are frequently complicated by restenosis with neointimal proliferation! ${ }^{10,16,17}$ Hosking et al reported that in swine there was no apparent difference in the proliferative responses of the normal systemic veins and the normal $\mathrm{PV}$ to the presence of an intravascular stent and they suggested that the final stent diameter within a vessel at the time of stent placement may determine the rate of reocclusion, particularly when the underlying substrate is abnormal with a tendency for neointimal proliferation ${ }^{24}$ We have found that, even in the pulmonary artery, a small vessel diameter is a risk factor for excessive late neointimal proliferation 25

In the present study, although the acute results of stenting

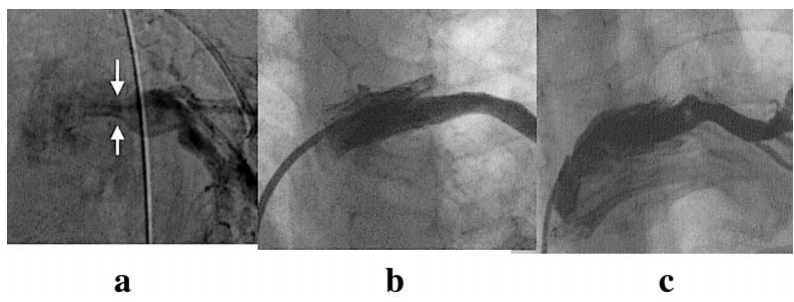

Fig 3. Selective angiograms of a left lower pulmonary vein in case 2. (a) Prior to implantation of a stent (arrow indicates stenosis). (b) After stent implantation. (c) F/U angiogram at 5 months. No significant restenosis is documented.

the PVs were promising, restenosis was a major limitation, as reported previously! $10,16,17$ However, repeated redilatations were usually effective, following a slight increase in stent diameter and a striking decrease in the intimal thickness. Furthermore we achieved long-term patency in 2 lesions dilated up to 8.4 and $5.6 \mathrm{~mm}$, respectively. Although further follow-up is mandatory, the final stent diameter within a vessel may be critical for long-term patency and we believe that aggressive redilatation may have a role in the therapy of this difficult disease.

The design of the stent strut may be another important determinant of late restenosis. We used 2 types of stent (ie, the original Palmaz and the Palmaz Corinthian), but we have not yet identified any difference between them because of the small number of lesions tested.

In conclusion, stenting acutely improves PV stenosis, but further investigations on effective measures to prevent restenosis are necessary. Medical treatment to prevent excessive intimal proliferation ${ }^{26}$ and innovative stent design may be required, but redilatation to achieve an adequate internal diameter of the PV is another option.

\section{Acknowledgments}

We thank Drs Peter M. Olley, Professor of Pediatrics, University of Alberta, and Setsuko Olley for their assistance in preparing the manuscript.

\section{References}

1. Driscoll DJ, Hesslein PS, Mullins CE. Congenital stenosis of individual pulmonary veins: Clinical spectrum and unsuccessful treatment by transvenous balloon dilation. Am J Cardiol 1982; 49: 1767 1772.

2. Bini RM, Cleveland D, Ceballos R, Bargeron LM, Pacifico AD, Kirklin JW. Congenital pulmonary vein stenosis. Am J Cardiol 1984; 54: $369-375$.

3. Lamb RK, Qureshi SA, Wilkinson JL, Arnold R, West RW, Hamilton DI. Total anomalous pulmonary venous drainage: Seventeen year surgical experience. J Thorac Cardiovasc Surg 1988; 96: 368-375.

4. van de Wal HJ, Hamilton DI, Godman MJ, Harinck E, Lacquet LK, van Oort A. Pulmonary venous obstruction following correction for total anomalous pulmonary venous drainage: A challenge. Eur J Cardiothorac Surg 1992; 6: 545-549.

5. Mendeloff EN, Spray TL, Huddleston CB, Bridges ND, Canter CB, Mallory GB. Lung transplantation for congenital pulmonary vein stenosis. Ann Thorac Surg 1995; 60: 903-906.

6. Bando K, Turrentine MW, Ensing GJ, Sun K, Sharp TG, Sekine Y, et al. Surgical management of total anomalous pulmonary venous connection: Thirty-year trends. Circulation 1996; 94(Suppl): II12II16.

7. Caldarone CA, Najm HK, Kadletz M, Smallhorn JF, Freedom RM, Williams WG, et al. Relentless pulmonary vein stenosis after repair of total anomalous pulmonary venous drainage. Ann Thorac Surg 1998; 66: $1514-1520$.

8. O'Laughlin MP, Perry SB, Lock JE, Mullins CE. Use of endovascular stents in congenital heart disease. Circulation 1991; 83: $1923-$ 1939. 
9. Hosking MCK, Benson LN, Nakanishi T, Burrows PE, Williams WG, Freedom RM. Intravascular stent prosthesis for right ventricular outflow obstruction. J Am Coll Cardiol 1992; 20: 373-380.

10. O'Laughlin MP, Slack MC, Grifka RG, Perry SB, Lock JE, Mullins CE. Implantation and intermediate-term follow-up of stents in congenital heart disease. Circulation 1993; 88: 605-614.

11. de Lezo JS, Pan M, Romero M, Medina A, Segura J, Pavlovic D, et al. Balloon-expandable stent repair of severe coarctation of aorta. $\mathrm{Am}$ Heart J 1995; 129: 10002-10008.

12. Magee AG, Brzezinska-Rajszys G, Qureshi SA, Rosenthal E, Zubrzycka M, Ksiazyk J, et al. Stent implantation for aortic coarctation and recoarctation. Heart 1999; 82: 600-606.

13. Mendelsohn AM, Bove EL, Lupinetti FM, Crowley DC, Lloyd TR, Fedderly RT, et al. Intraoperative and percutaneous stenting of congenital pulmonary artery and vein stenosis. Circulation $1993 ; \mathbf{8 8}(\mathrm{Pt}$ 2): $210-217$

14. Fogelman R, Nykanen D, Smallhorn JF, McCridle BW, Freedom RM, Benson LN. Endovascular stents in the pulmonary circulation: Clinical impact on management and medium-term follow-up. Circulation 1995; 92: 881-885.

15. Hatai Y, Nykanen DG, Williams WG, Freedom RM, Benson LN. The clinical impact of percutaneous balloon expandable endovascular stents in the management of early postoperative vascular obstruction. Cardiol Young 1996; 6: 48-53.

16. Cullen S, Ho SY, Shore D, Lincoln C, Redington A. Congenital stenosis of pulmonary veins: Failure to modify natural history by intraoperative placement of stents. Cardiol Young 1994; 4: 395 398.

17. Coles JG, Yemets I, Najm HK, Lukanich JM, Perron J, Wilson GJ, et al. Experience with repair of congenital heart defects using adjunctive endovascular devices. J Thorac Cardiovasc Surg 1995; 110: $1513-1519$.

18. van Son JA, Danielson GK, Puga FJ, Edwards WD, Driscoll DJ. Re- pair of congenital and acquired pulmonary vein stenosis. Ann Thorac Surg 1995; 60: 144-150.

19. Sadr IM, Tan PE, Kieran MW, Jenkins KJ. Mechanism of pulmonary vein stenosis in infants with normally connected veins. Am J Cardiol 2000; 86: $577-579$.

20. Breinholt JP, Hawkins JA, Minich LA, Tani LY, Orsmond GS, Ritter $\mathrm{S}$, et al. Pulmonary vein stenosis with normal connection: Associated cardiac abnormalities and variable outcome. Ann Thorac Surg 1999; 68: $164-168$.

21. Hashmi A, Abu-Sulaiman R, McCrindle BW, Smallhorn JF, Williams WG, Freedom RM. Management and outcomes of right atrial isomerism: A 26-year experience. J Am Coll Cardiol 1998; 31: $1120-$ 1126.

22. Smallhorn JF, Burrows P, Wilson G, Coles J, Gidlay DL, Freedom RM. Two dimensional and pulsed Doppler echocardiography in the postoperative evaluation of total anomalous pulmonary venous connection. Circulation 1987; 76: 298-305.

23. Jenkins KJ, Sanders SP, Coleman L, Mayers JE, Colan SD. Pulmonary vein size and outcome in infants with totally anomalous pulmonary venous connection (abstract). Circulation 1991; 84(Suppl II): 351.

24. Hosking M, Redmond M, Allen L, Broecker L, Keaney M, Lebeau J, et al. Responses of systemic and pulmonary veins to the presence of an intravascular stent in a swine model. Cathet Cardiovasc Diagn 1995; 36: 90-96.

25. Tomita H, Yazaki S, Kimura K, Ono Y, Yamada O, Yagihara T, et al. Late neointimal proliferation following implantation of stents for relief of pulmonary arterial stenosis. Cardiol Young 2002, 12: 125129.

26. Jenkins KJ, Tan PE, Perry SB, Colan SD, Gauvreau K, Goff DA, et al. Proliferative pulmonary vein stenosis: Variable patterns of prognosis and preliminary results using adjunctive chemotherapy (abstract). Circulation 2001; 104(Suppl II): II-587. 